\title{
The Influence of Maternal Meta-Emotion Philosophy on Mother-Child Reciprocal Affect Reactions During Task Interactions
}

\author{
Eun Young Nahm, So Eun Park \\ Department of Child Studies, Seoul Women's University, Seoul, Korea \\ 어머니 상위정서철학이 어머니-자녀 상호작용에서 나타난 \\ 정서반응에 미치는 영향 \\ 남은영, 박소은 \\ 서울여자대학교 아동학과 아동심리학전공
}

Objective: The purpose of this study was to analyze the relationship between maternal meta-emotion philosophy and mother-child reactions during their interactions.

Methods: The study sample consisted of 44 mothers and their 5 -year-old children. Data were collected by a semi-structured meta-emotion philosophy interview about emotions and by observing a mother - child interaction teaching task for 15 minutes. All interviews and interaction task data were quantitatively processed.

Results: Our analysis showed that maternal emotional regulation reduces maternal negative affects. We also found that maternal emotional coaching of the child is a factor that decreases the child's negative emotional reactions. Moreover mothers who can regulate better their own emotions have an influence on the pattern of 'maternal neutral emotion - child positive emotion', while mothers who accept the child's emotions well have influence on the 'maternal positive emotion - child positive emotion' pattern. Finally, maternal emotional acceptance, emotional regulation and emotional awareness of the child's emotion led to a reduction of the 'maternal negative emotion - child negative emotion' patterns.

Conclusion: These results suggest that maternal meta-emotion philosophy is a foundation for the actual mother-child interaction and is an important factor in mother-child reciprocal affect patterns.

Keywords: maternal meta-emotion philosophy, mother-child reciprocal affect reaction, task interaction.

$$
\text { 서론 }
$$

정서는 사회적 상호작용의 단서로서 대인 간 상호관계의 효 과적인 연결을 돕는다(Fischer \& Manstead, 2008). 특히 어머 니-자녀 간 상호작용은 정서사회화 과정 안에서 자녀와의 역

Corresponding Author: EunYoung Nahm, Department of Child Studies, Seoul Women's University, 621, Hwarang-ro, Nowon-gu, Seoul, Korea E-mail: nahmey@swu.ac.kr
동적인 정서적 교류를 통해 이루어지며(Paavola, Kunnari, \& Moilanen, 2005; Webster-Stratton, Reid, \& Hammond, 2004), 이러한 정서들은 개인 내적 신념 및 가치관과의 선제적 상호 작용을 거친 후 표현된다(Chen, Lin, \& Li, 2012; Krippl, AstScheitenberger, Bovenschen, \& Spangler 2010). 이는 어머니-자

(C)The Korean Association of Child Studies

This is an Open Access article distributed under the terms of the Creative Commons Attribution Non-Commercial License (http:// creativecommons.org/licenses/by-nc/4.0) which permits unrestricted noncommercial use, distribution, and reproduction in any medium, provided the original work is properly cited. 
녀 상호작용 가운데 나타나는 어머니의 정서반응들이 그 근 저에 깔린 정서에 대한 신념 및 철학과 밀접한 연관이 있음 을 보여준다(Dunsmore \& Karn, 2001; Morey, Gentzler, Creasy, Oberhauser, \& Westerman, 2013).

Gottman, Katz와 Hooven (1996)은 정서사회화의 일환으로 정서에 대한 느낌과 생각, 즉 '누군가의 슬픔에 대한 분노 감 정'을 넘어, 본인이 경험하는 정서와 타인이 경험하는 정서에 대한 가치관, 신념, 태도, 생각 및 느낌을 포함하는 '상위정서 철학(meta-emotion philosophy)' 개념을 제시하였다. 이는 감정 정보를 처리하고 조절하여 환경을 효율적으로 다루기 위한 개 인의 능력에 초점을 맞춘 정서지능(Salovey \& Mayer, 1990)과 는 구별되는 것으로, 상위정서철학은 정서적 능력에 대한 평 가라기 보다는 정서에 대한 가치관, 태도, 신념 등의 차원으 로 개인이 정서에 대해 가지고 있는 상위인지적 개념이다. 따 라서 여기엔 옳고 그르거나 더 높고 낮음이 존재하지 않지만 정서에 접근하는 방식에 영향을 미친다(Gottman et al., 1996; Norman \& Furnes, 2016).

정서사회화의 측면에서 부모의 상위정서철학에 따라 아동 의 정서적 발달에 긍정 혹은 부정적 영향을 줄 수 있음이 여러 선행연구들을 통해 보고되고 있다(Gottman et al., 1996; Katz, Maliken, \& Stettler, 2012; Shortt, Stoolmiller, Smith-Shine, Eddy, \& Sheeber, 2010). 예로 부모가 부정적 정서에 대해 긍정적 태 도와 가치관을 가지고 있는 경우 자신의 정서 뿐 만 아니라 자 녀가 보이는 부정적 정서에 대해서도 수용과 공감의 폭이 넓 고, 또한 정서적 교감의 기회로 생각하기 때문에 이를 통해 자 녀가 정서적으로도 더 유능해지게 된다. 더 구체적으로 상위정 서철학에서 유아의 부정정서에 대한 어머니의 높은 인식 및 코 칭은 아동의 또래 관계에 긍정적 영향을 줄 뿐 아니라(Katz \& Windecker-Nelson, 2004), 어머니 자신에 대한 높은 정서수용이 청소년 자녀의 자아존중감에도 긍정적 영향이 있음이 밝혀졌 다(Katz \& Hunter, 2007). 반면 부모가 부정적 정서를 해롭다고 생각하는 경우, 자녀가 부정적 정서를 보일 때 축소하거나 처 벌하는 경향이 있고, 이는 아동의 정서발달에 있어 부정적 영 향을 가져오게 된다(Gottman et al., 1996; Katz, et al., 2012).

Gottman과 동료들이 제시한 부모 상위정서철학과 유사한 개념으로 정서관련 양육신념에 관한 연구들이 있다. 관련된 일 련의 연구결과들 역시, 자녀양육에 대해 부모가 가지고 있는 정서에 대한 태도 및 의식이 아동의 정서사회화 발달에 중요한 변인으로 보고하고 있다(Dusmore \& Karn, 2001; Jeong \& Park, 2012). 그러나 정서에 대한 부모의 양육신념은 상위정서철학 과 유사한 부분이 있으나 보다 포괄적인 양육관련 신념에 초
점을 두고 있기에 상위정서철학이 다루고 있는 부모 자신의 정 서에 대한 부분과 실제 양육에 대한 적용까지 확인하기는 어렵 다(Cervantes \& Seo, 2005; Dunsmore \& Karn, 2001, Halberstadt, Thompson, Parker, \& Dunsmore, 2008). 따라서, 자녀의 정서경 험 및 부모 자신의 정서경험에 대한 전반적 신념과 가치관을 중심으로 하는 상위정서철학은 부정정서경험에 대한 어머니 의 정서에 대한 가치관을 보다 명확하게 담아낼 수 있고, 이러 한 상위 인지적 개념이 실제 자녀와의 상호작용 속에서도 그대 로 적용이 되는지를 살펴보는 것은 정서사회화의 과정에 대한 흥미로운 인과 관계를 밝혀줄 수 있으리라 본다.

상위정서철학은 부정적 정서에 관한 부모 자신과 자녀 의 정서적 경험을 질적으로 평가하는 상위정서인터뷰(metaemotion interview)를 통해 탄생하였다. 인터뷰는 크게 부모차 원과 아동차원으로 구분되며, 부모차원은 부모 자신의 정서 경험에 대한 것으로 자신의 정서에 대한 '인식', '수용', '조절' 이, 아동차원에는 자녀의 정서 경험에 대한 부모의 '인식', '수 용', '코칭', ‘조절'이 포함된다(Katz, Mittman, \& Hooven, 1994). 구체적으로 부모가 자신의 정서 및 자녀의 정서에 대해 인식 수준이 높고 자녀의 정서를 코칭하는 상위정서철학을 가진 경 우, 자녀와의 관계에서 보다 허용적인 행동을 보이는 것으로 나타났다(Nahm, 2006). 그리고 자녀의 정서에 대한 지지적인 신념을 가진 어머니는 자녀의 부정정서경험을 격려하고 비지 지적 반응을 적게 보이는 반면(Wong, Diener, \& Isabella, 2008), 부정적 신념을 가진 경우 자녀의 정서표현을 최소화거나 처벌 하는 경향이 있음이 밝혀졌다(Gottman et al., 1996). 선행연구 들은 또한 자신 및 자녀의 정서를 잘 인식하고 수용, 공감하며 정서에 대해 코칭하는 어머니의 자녀들이 또래관계에서 인기 있는 아동으로 지목받으며 사회적으로도 유능한 아이로 평가 되었다고 보고한다(Katz \& Hunter, 2007; Song \& Nahm, 2013). 뿐만 아니라 자녀의 높은 신체적 자기조절, 낮은 행동문제, 높 은 수준의 학업성취와도 관련이 있었다(Gottman et al., 1996). 한국이민자 부모를 대상으로 한 Nahm (2006)의 연구를 시작 으로 국내에서도, 어머니의 상위정서철학과 아동의 행동문제 및 사회정서발달, 또래관계의 관계를 살펴본 연구들이 꾸준 히 이루어지고 있다(Choi \& Nahm, 2016; Kim \& Nahm, 2013; Song \& Nahm, 2013). 이처럼 다수의 연구들을 통해 어머니의 상위정서철학이 아동의 발달적 결과 및 정서적 능력에도 기저 를 이루는 중요한 변인임을 제안하고 있지만(Stettler \& Katz, 2014), 어머니의 상위정서철학이 정서사회와 과정 안에서 실 제 어머니-자녀 상호작용, 특별히 부정정서가 상승되는 상황 내 정서반응들과 어떠한 관계가 있는지를 통합적으로 살펴본 
학문적 시도는 찾아보기 어렵다.

한편 어머니와 자녀가 상호작용하며 주고받는 상호호혜 적 정서반응(reciprocal affect reaction)은 상호작용 가운데 드러 난 정서반응을 넘어, 상호 간의 조절과 적응의 과정으로(Kelly $\&$ Barnard, 2000), 상호 정서적 교류를 통해 확장되며(Carson $\&$ Parke, 1996), 자녀의 정서에 가장 중요한 부분으로 작용한다 (Osofsky \& Thompson, 2000). 이는 Siegel (1999)이 제안한 부모자녀 관계에서의 '정서적 공명'으로 설명할 수 있는데, 부모의 정서가 미묘한 언어적, 비언어적 단서들을 통해 자녀와의 공유 된 상태 내에서 공명하며, 자녀의 정서경험을 강화시키고 나아 가 신경학적으로 자녀의 기억 안에 뿌리깊게 심어지도록 하는 역할을 함을 의미한다. 예로, 상호작용 내에서 부정적인 상호 호혜적 정서교류가 고조될 경우, 상승된 아버지의 부정정서는 자녀의 더 강한 부정정서반응을 이끌고, 자녀의 부정적 정서 각성을 증가시키는 결정적 역할을 한다(Carson \& Parke, 1996). 이러한 연구들은 어머니-자녀 상호작용 가운데 나타나는 어머 니 정서반응과 자녀 정서반응의 상호호혜적 정서적 교류에 대 한 탐색이 정서사회화 이해에 무엇보다 중요할 뿐 아니라, 어 머니-자녀 상호작용 연구의 필요성을 뒷받침한다.

이에 Nahm과 Park (2017)은 어머니와 자녀의 실질적인 상 호작용을 질적으로 관찰하여 부정정서에 대한 어머니의 정서 반응에 따른 자녀의 정서반응을 규명하였다. 연구에 따르면, 스트레스가 유발되는 과제 상황 하에서 정서조절 수준이 낮아 답답하고 불안한 부정정서를 그대로 표현하는 어머니의 자녀 는 실제 상호작용 동안 강한 부정적 정서를 경험하였고, 반면 어머니가 자녀에게 긍정정서를 많이 보일수록 자녀 또한 과 제수행에 즐거움을 보이는 것으로 나타났다(Katz et al., 2012; Nahm \& Park, 2017; Shortt et al., 2010). 그러나 어머니-자녀의 실질적 상호작용을 살펴본 연구들은 대부분이 상호작용 상황 속에서 드러난 정서반응의 지속시간(Nahm \& Park, 2017) 혹 은 양육행동특성(Shin, Park, Kim, \& Doh, 2015)에 초점을 두 는데 그쳤다.

이에 본 연구에서는 기존 연구들의 확장으로 학령 전 아동 어머니의 상위정서철학이 실제 부정정서가 상승된 어머니-자 녀 상호작용에서 나타난 정서반응들에 어떠한 영향을 미치는 지 확인하고, 나아가 정서반응의 단편적 분석을 넘어 반복되 는 정서적 교류 패턴을 탐색하고자 한다. 특히 상호호혜적 정 서반응패턴은 정서반응을 촉발시키는 어머니의 정서반응 혹 은 어머니 정서반응에 뒤따르는 자녀의 정서반응의 상호패턴 으로, 어머니-자녀 간 상호 정서 교류의 흐름과 정서적 특성을 확인할 수 있다.
무엇보다 만 5세는 생물학적인 뇌 발달에 의해 정서 이해 및 정서 조절능력이 발달하여, 정서사회화 과정에 매우 결정 적인 시기이다(Bernier, Carlson, \& Whipple, 2010). 또한 상대 적으로 부모와 함께 보내는 시간이 많아 부모의 영향력 또 한 더 민감하게 작용한다(Meyer, Railes, Virmani, Waters, \& Thompson, 2014). 따라서 이 시기 어머니와 자녀의 상호 연결 성과 양방향성에 대한 정서반응패턴 연구는 어머니-자녀 관 계를 이해하는데 큰 도움을 줄 것으로 보인다.

특별히 상위정서철학 인터뷰를 사용하여 어머니 상위정서 적 특성에 대한 풍부한 질적 정보를 수집하고 이를 수치화하 여 양적으로 분석하는 과정을 통해 정서에 대한 보다 정확하 고 세밀한 접근을 시도하였다. 또한 어머니-자녀 상호작용 실 험에는 과제 성공에 대한 요구와 시간제한 설정을 통해 자연 스러운 스트레스를 상승시키고 부정적 정서를 유발시켜, 보다 다양한 정서반응을 이끌어 내고자 하였다. 더불어 실험 관찰 자료는 컴퓨터를 활용한 초 단위 정서분석프로그램을 통해 상 호작용 내에서 나타나는 미세한 정서변화를 명확하게 측정하 고자 하였다. 이에 따른 구체적인 연구문제는 다음과 같다.

\section{연구문제 1}

어머니 상위정서철학은 상호작용에서 나타난 어머니-자녀 정 서반응에 어떠한 영향을 미치는가?

\section{연구문제 2}

어머니 상위정서철학은 상호작용에서 나타난 어머니-자녀 상 호호혜적 정서반응패턴에 어떠한 영향을 미치는가?

\section{연구방법}

\section{연구대상}

본 연구는 서울시에 살고있는 만 5 세 자녀와 그들의 어머니를 총 44쌍을 대상으로 하였다. 아동의 성별은 남아 27 명 (61.4\%), 여아 17 명(38.6\%)이었으며, 어머니의 평균 연령은 37.36세였 다. 어머니의 학력은 대학원 졸업이 5명(11.4\%), 대학교 졸업 이 20 명(45.5\%), 고등학교 졸업이 19 명(43.2\%)이었다. 가정 의 월수입은 200 만원 미만이 8 명(18.2\%), 200 만원 이상 400 만 원 미만이 24명(54.5\%), 400만원 이상 600만원 미만이 12명 (18.2\%), 600만원 이상이 4명(9.1\%)이었다. 


\section{연구도구}

\section{어머니 상위정서철학}

어머니 상위정서철학 측정을 위해 Nahm (2006)이 번안한 Katz 와 Gottman (1986)의 부모 상위정서인터뷰(parent meta-emotion interview)를 사용하였다. 인터뷰는 슬픔과 분노 정서에 대해, 정서의 표현과 억제 혹은 조절 등 각 정서에 대한 가치관 및 자 녀의 정서경험에 대한 그들의 신념과 자녀를 향한 행동적 반 응에 관한 개방형 질문을 통해 피면접자의 정서에 대한 주관 적 경험과 전반적인 철학 및 가치관을 살펴보도록 이루어져있 다(예: 슬플 때 어떤 느낌이 드세요? 슬픔을 극복하거나 이기기 위해 하시는 것이 있나요? 자녀가 슬프면 어떤 생각이 드세요? 자녀에게 슬픔에 대해 가르쳐주고 싶은 것이 있나요?).

개별 인터뷰는 독립된 공간에서 40-60분 정도 소요되며, 모 든 인터뷰 자료는 비디오카메라로 녹화하였다. 녹화된 인터뷰 자료는 Katz 등(1994)이 제작하고 Nahm (2006)이 번안한 상 위정서코딩체계(meta-emotion coding system)를 통해 분석하였 다. 상위정서코딩체계는 다수의 연구를 통해 신뢰도와 타당도 가 확보된 코딩도구로(Katz \& Windecker-Nelson, 2004), 두 가 지의 하위영역(어머니 본인의 정서에 대한 상위정서철학, 자 녀의 정서에 대한 상위정서철학)으로 나뉜다. 인터뷰 자료의 분석은 코딩전문가와 7 개월 이상의 집중적 코딩 훈련과정을 거쳐 평정자간 일치도가 .70 이상임을 검증받은 3 명의 연구자 가 전체 데이터의 $30 \%$ 를 더블코딩하였다. 평정자 간 신뢰도 (ICC)는 .74 .91로 나타났다.

어머니 본인의 정서에 대한 상위정서철학 어머니 본인이 일 상생활에서 경험하는 부정적 정서(슬픔과 분노)에 대한 느낌 및 생각에 대해 반 구조화된 인터뷰를 통해 질문한다. 코딩분 석의 하위항목들은 정서인식, 정서수용, 정서조절로 나뉘며, 상위정서인터뷰 반응에 따라 매우 일치, 일치, 중립, 불일치, 매우 불일치의 5점 척도로 코딩되며, 인터뷰로부터 얻는 정보 가 없을 경우, 각 하위항목의 평균점수(예, 2.9 혹은 3.1)인 '알 수 없음'으로 코딩된다. 정서 인식은 12 개의 문항으로 각 정서 에 대한 원인을 인식하고 있는지 신체적 지각에 대해 기술하 는지 등의 개념이 포함된다(가능한 점수 배점, 24-48점). 정서 수용은 감정을 표현함에 있어 편안함을 느끼는지, 감정조절 및 통제의 중요성을 언급하는지 등의 총 17 개의 문항으로 구 성된다(가능한 점수 배점, 26-77.9점). 정서조절은 총 12 개의 문항으로 감정의 격렬함을 조절하는데 어려움이 있는지 등의
개념을 포함한다(가능한 점수 배점, 17-47.9점). 각 항목의 점 수들은 슬픔과 분노로 각각 나누어 인터뷰하고 점수 산출 후 에는 슬픔과 분노 점수가 더해진다. 따라서 어머니 정서인식 배점의 총점은 96점, 정서수용 155.8점, 정서조절 95.8점이다.

자녀의 정서에 대한 상위정서철학 자녀의 정서에 대한 어머 니의 상위정서철학에서는 일상에서 자녀의 부정적 정서(슬 픔과 분노)에 대한 어머니의 인식방식과 태도, 행동을 측정한 다. 코딩분석의 하위요인은 자녀의 정서인식, 정서수용, 정서 코칭, 정서조절로 나뉘게 되며, 코딩방식은 어머니차원과 동 일하다. 자녀의 정서인식은 총 9 개의 문항으로 자녀의 감정 경 험을 구별하는지 통찰력을 갖는지 등의 개념을 포함한다(가 능한 점수 배점, 17-36점). 자녀의 정서수용은 자녀의 감정표 현에 편안함을 느끼는지, 감정을 공감해주는지 등의 총 13 개 의 문항으로 구성된다(가능한 점수 배점, 25-52점). 자녀의 정 서코칭은 총 11 개의 문항으로 어머니가 자녀의 감정 경험을 존중해주고 적합한 표현과 규칙을 가르치는지 등이 포함된다 (가능한 점수 배점, 23.1-46점). 자녀의 정서조절은 총 9개의 문항으로 자녀가 감정조절을 힘들어하는지 자녀의 극복기술 을 알고있는지 등의 개념으로 구성되어있다(가능한 점수 배 점, 12-39점). 각 항목의 점수들은 슬픔과 분노로 각각 나누어 인터뷰하고 점수 산출 후에는 슬픔과 분노 점수가 더해진다. 자녀의 정서에 대한 정서인식 배점의 총점은 72 점, 정서수용 은 104 점, 정서코칭은 92 점, 정서조절은 78 점이다.

\section{어머니-자녀 상호작용 실험}

어머니와 자녀의 상호작용 실험을 위해 Nahm (2006)이 고안 한 젠가블록 과제실험(teaching-task)을 실시하였다. 이 과제는 15 분의 제한된 시간 설정과 과제성공 시 선물을 제공한다는 안내를 통해, 어머니와 자녀의 자연스러운 긴장과 스트레스를 유발시키고 과제실험에 집중적으로 몰입할 수 있도록 돕는다. 세부규칙은 3 개의 블록이 하나의 층으로 구성된 총 18 개 층의 젠가 탑을 놓고, 한 손으로 탑의 하단에 있는 블록들을 꺼내 다 시 탑 위로 하나씩 쌓아올려, 8 개의 탑을 만들어야 한다. 제한 시간 동안 어머니는 언어적 지시를 통해서만 자녀의 과제수행 을 도울 수 있으며, 제한시간 내에서는 탑이 무너지더라도 원 하는 만큼 다시 시도할 수 있다.

과제실험은 비디오 카메라를 통해 녹화하였고, 코딩을 위 해 Kahen이 개발하고 Nahm (2006)이 개정한 Kahen정서코 딩체계(Kahen Affeect Coding System [KACS])를 사용하였다. 
$\mathrm{KACS}$ 의 하위요인은 크게 어머니의 개입행동과 정서반응, 자 녀 정서반응으로 이루어져있으나, 본 연구에서는 어머니의 정 서반응과 자녀의 정서반응만을 살펴보았다. 어머니 정서반응 은 긍정정서(애정형, 유머형), 부정정서(경멸형, 부정형: 분노/ 좌절/비난), 긴장형(긴장형/긴장형 유머), 중립으로 이루어져 있다. 마지막으로 자녀의 정서반응은 긍정정서(애정형, 유머 형) 부정정서(부정형: 분노/초조함/좌절/불순종형, 슬픔/보채 기형), 긴장형(긴장형/긴장형 유머), 중립으로 구분된다.

상호작용 분석은 INTERACT 8 (Mangold, 2008)을 사용하 여 컴퓨터로 초단위 코딩하였다. 프로그램 내에 KACS 각 하 위요인과 키보드의 각 알파벳을 매치하여 입력한 다음, 녹화 한 영상이 재생되는 동안 각 하위요인에 해당하는 알파벳을 실시간 초단위로 코딩한다. 코딩된 자료는 각 하위요인의 지 속시간을 의미한다. 평정의 신뢰도를 위해 6 개월 간의 정서코 딩체계 훈련을 통해 평정자 간 일치도를 검증 받은(ICC > .7) 연구원과 전체 데이터의 $25 \%$ 를 더블 코딩하였으며, 본 도구 의 평정자 간 신뢰도(ICC)는 .75- .89 이다.

\section{자료분석}

상위정서인터뷰 코딩 및 Kahen정서코딩체계를 통해 수집된 자료는 PASW 18.0 (SPSS INC., Chicago, IL)프로그램을 사용 하여 분석하였다. 연구참여자의 인구학적 특성을 살펴보기 위 해 평균과 표준편차, 빈도와 백분율을 산출하였다. 어머니의 상위정서철학, 상호작용 내에서의 정서반응 및 자녀의 정서반 응 간의 관계를 살펴보기 위해 Pearson의 적률상관 계수를 산 출하였다. 다음으로 이들 변인의 인과관계를 확인을 위해 다 중회귀분석을 실시하였다. 이때 다중공선성 여부를 살펴보기 위해, 공차한계가 0.1 이상(0.41 0.68), 분산팽창요인(VIF) 값 이 모두 10 이하(3.54 5.13)임을 확인하였으며, 잔차 간의 상 호독립성을 위해 Durbin-Waston 통계량이 2에 근접함을 확인 하였다. 특별히 본 연구에서는 어머니-자녀 상호작용의 패턴 분석을 위해 Kahen정서코딩체계 하위요인의 어머니변인 vs 아동변인 간 코드를 새롭게 결합하여 INTERACT 8 프로그램 내 상황의존도 분석(contingency analysis)을 실시하였다. 자녀 의 정서반응이 어머니의 특정 정서반응에 얼마나 자주 뒤따르 는지를 살펴봄으로서, 어머니의 정서반응에 따를 아동의 정서 반응 패턴을 확인할 수 있는 분석방법이다. 이는 주어진 시간 동안 각 코드결합의 빈도를 산출하도록 돕고 더불어 구체적인 반응 패턴을 확인하도록 한다. 전체 결합된 코드의 수는 16 개 (어머니변인 수: 4 , 아동변인 수: 4 )이며, 변인의 축소를 목적으
로 주성분분석(PCA)을 실시하였다. 주성분분석은 최초의 정 보를 최소한의 요인으로 축소시키고자 할 때 사용된다. 축소 과정에서 개별 차원이 갖는 절대적 차이는 적지만 중요한 의 미를 갖는 변수가 누락되지 않도록 하였다(Jolliffe, 2002). 세 부적으로 배리맥스(Varimax)직각회전을 통해 상호작용 동안 의 어머니-자녀 상호작용 패턴 요인을 추출하였다. 요인의 수 를 추출하기 위해 설명된 총분산과 스크리 검정, 최소 고유값 기준 등을 종합적으로 고려하여 총 6 개의 요인이 적당한 것으 로 나타났다. 또한 고유치가 1.0 이상인 요인이 4개로 나타났 으며, 전체 분산의 $84.86 \%$ 를 설명하고 있다. 각 요인은 '어머 니 중립정서 $(\mathrm{MNuE})$ - 자녀 긍정정서 $(\mathrm{CPE})$ ', '어머니 긍정정 서(MPE) - 자녀 긍정정서(CPE), '어머니 부정정서(MNE) - 자 녀 부정정서(CNE)', '어머니 부정정서(MNE) - 자녀 중립정서 $(\mathrm{CNuE})^{\prime}$ 이다.

\section{연구결과}

\section{주요변인들의 기술통계 및 상관분석}

어머니 상위정서철학과 상호작용에서 나타난 어머니-자녀 정 서반응의 각 하위변인에 대한 기술통계 분석(Table 1) 및 상관 관계 분석결과는 다음과 같다(Table 2). 어머니 자신에 대한 정 서조절 수준은 어머니의 부정정서반응 $(r=-.38, p<.01)$ 간 관 계에서 부적상관을 보였다. 한편 어머니 상위정서철학 하위요 인 중 자녀의 정서에 대한 어머니 정서코칭은 아동의 부정정 서반응과 부적상관이 나타났다 $(r=-.31, p<.05)$. 그리고 자녀 의 정서에 대한 어머니 정서조절은 어머니의 긴장형 정서 $(r=$ $-.32, p<.05)$ 간 부적상관이 있음을 확인하였다.

\section{어머니 상위정서철학이 상호작용에서 나타난 어머니-자녀 정서반응에 미치는 영향}

어머니 상위정서철학이 과제 상호작용에서 나타난 어머니-자 녀 정서반응에 미치는 영향력을 분석하기 위해 다중회귀분석 을 실시하였다. 이 중 유의한 영향을 미치는 결과만을 Table 3 에 제시하였다. 어머니 상위정서철학 하위요인 중 어머니 자 신의 정서에 대한 정서조절은 어머니의 부정정서반응에 영향 을 미쳤으며, 이는 $19 \%$ 의 설명력을 보였다 $(F=3.07, p<.05$, $\beta=-.73, p<.01)$. 또한 자녀의 정서에 대한 어머니의 상위정서 철학 중 정서코칭이 아동의 부정정서반응에 미치는 영향의 설 
Table 1

Descriptive Statistics

\begin{tabular}{lrr}
\hline \multicolumn{1}{c}{ Variable } & \multicolumn{1}{c}{$M$} & \multicolumn{1}{c}{$S D$} \\
\hline Maternal meta-emotion philosophy & & \\
Emotional awareness & 85.45 & 4.78 \\
Emotional acceptance & 107.25 & 6.46 \\
Emotional regulation & 77.99 & 6.53 \\
Emotional awareness of child's emotion & 62.51 & 4.51 \\
Emotional acceptance of child's emotion & 77.67 & 4.17 \\
Emotional coaching of child's emotion & 70.01 & 5.45 \\
Emotional regulation of child's emotion & 57.81 & 4.92 \\
Maternal affect & & \\
Positive & 96.21 & 66.74 \\
Negative & 28.63 & 53.37 \\
Tension & 118.56 & 76.20 \\
Neutral & 679.45 & 111.85 \\
Child affect & & \\
Positive & 51.90 & 58.46 \\
Negative & 28.61 & 24.01 \\
Tension & 187.29 & 156.22 \\
Neutral & 616.34 & 145.64 \\
\hline
\end{tabular}

Note. $N=44$.
명력은 34\%로, 통계적으로 유의한 것으로 나타났다 $(F=2.63$, $p<.05, \beta=-.40, p<.05)$.

$$
\begin{aligned}
& \text { 어머니 상위정서철학이 상호작용에서 나타난 } \\
& \text { 어머니-자녀 상호호혜적 정서반응패턴에 미치 } \\
& \text { 는 영향 }
\end{aligned}
$$

어머니 상위정서철학이 어머니-자녀 상호호혜적 정서반응패 턴에 미치는 영향력을 분석하기에 앞서, 어머니 상위정서철학 과 어머니-자녀 상호호혜적 정서반응패턴 간 상관분석을 실시 한 결과를 Table 4 에 제시하였다. 어머니 자신의 정서조절 수준 이 높을수록 '어머니 중립정서 - 자녀 긍정정서' 패턴이 많이 나 타났다 $(r=.41, p<.01)$. 그리고 자녀의 정서에 대한 정서수용과 '어머니 긍정정서 - 자녀 긍정정서' 패턴은 정적상관을 보였다 $(r$ $=.40, p<.05)$. 다음으로 '어머니 부정정서 - 자녀 부정정서' 패 턴은 어머니 자신의 정서수용 $(r=-.42, p<.01)$, 어머니 자신의 정서조절 $(r=-.32 p<.05)$, 자녀의 정서에 대한 정서인식 $(r=-.40$, $p<.01)$ 과 부적상관을 보였다. 다시말하면, 자신의 정서수용과 정서조절 수준이 높으며, 자녀의 정서에 대한 인식 수준이 높 은 어머니들은 자녀와의 상호작용 내에서 '어머니 부정정서 -

\begin{tabular}{|c|c|c|c|c|c|c|c|c|c|c|c|c|c|c|}
\hline & 1 & 2 & 3 & 4 & 5 & 6 & 7 & 8 & 9 & 10 & 11 & 12 & 13 & 14 \\
\hline \multicolumn{15}{|c|}{ Maternal meta-emotion philosophy } \\
\hline 1 & - & & & & & & & & & & & & & \\
\hline 2 & $.46^{* *}$ & - & & & & & & & & & & & & \\
\hline 3 & .16 & $.34^{*}$ & - & & & & & & & & & & & \\
\hline 4 & $.41^{* *}$ & $.32^{*}$ & -.07 & - & & & & & & & & & & \\
\hline 5 & .20 & $.46^{* *}$ & $.44^{* *}$ & $.31^{*}$ & - & & & & & & & & & \\
\hline 6 & $.42^{* *}$ & $.56^{* *}$ & .27 & $.53^{* *}$ & $-.64^{* *}$ & - & & & & & & & & \\
\hline 7 & .06 & .15 & $.45^{* *}$ & .26 & $.56^{* *}$ & $.34^{*}$ & - & & & & & & & \\
\hline \multicolumn{15}{|c|}{ Maternal affect } \\
\hline 8 & .08 & -.19 & .16 & -.07 & .01 & -.05 & -.05 & - & & & & & & \\
\hline 9 & .13 & -.02 & $-.38^{*}$ & .06 & -.25 & -.04 & -.14 & $-.42^{* *}$ & - & & & & & \\
\hline 10 & .08 & .05 & .30 & .09 & .03 & .03 & $-.32 *$ & -.06 & .14 & - & & & & \\
\hline 11 & .02 & .10 & -.13 & -.22 & .02 & -.09 & -.06 & -.18 & -.13 & $-.56^{* *}$ & - & & & \\
\hline \multicolumn{15}{|c|}{ Child affect } \\
\hline 12 & -.06 & -.21 & -.05 & -.04 & .04 & -.10 & -.18 & $.63^{* *}$ & -.26 & -.24 & .02 & - & & \\
\hline 13 & -.01 & -.14 & -.19 & -.06 & -.05 & $-.31^{*}$ & -.21 & .07 & .15 & .51 & -.04 & .13 & - & \\
\hline 14 & .22 & .17 & .28 & .11 & .11 & .14 & .11 & -.21 & $.48^{*}$ & $.66^{* *}$ & $-.31^{*}$ & $-.39^{* *}$ & .13 & - \\
\hline 15 & .01 & .19 & -.08 & -.18 & .04 & .03 & .03 & .03 & -.23 & $-.51^{* *}$ & $.54^{* *}$ & .02 & -.27 & $-.61^{* *}$ \\
\hline
\end{tabular}

Table 2

Correlations of Related Variables

Note. $N=44 ; 1$ = emotional awareness; 2 = emotional acceptance; 3 = emotional regulation; 4 = emotional awareness of child's emotion; $5=$ emotional acceptance of child's emotion; $6=$ emotional coaching of child's emotion; $7=$ emotional regulation of child's emotion; $8=$ positive; 9 = negative; 10 = tension; 11 = neural; 12 = positive; 13 = negative; $14=$ tension; $15=$ neutral.

${ }^{*} p<.05 .{ }^{* *} p<.01$. 
자녀 부정정서' 패턴이 적게 나타남을 의미한다.

마지막으로, 다중회귀분석을 실시하고 유의한 영향을 미

치는 결과만을 Table 5에 제시하였다. 그 결과 어머니의 정서
조절 수준은 ‘어머니 중립정서 - 아동 긍정정서' 패턴에 영향 을 미치는 것으로 나타났으며 $(t=2.52, p<.05), 31 \%$ 의 설명력 을 보였다 $(F=4.55, \mathrm{p}<.05)$. '어머니 긍정정서 - 아동 긍정정서'

Table 3

Multiple Regression Analysis: Maternal Meta-Emotion Philosophy as Predictor of Maternal Affect and Child Affect

\begin{tabular}{|c|c|c|c|c|c|}
\hline Dependent variable & Independent variable & $\beta$ & $t$ & $R^{2}$ & F \\
\hline \multirow[t]{7}{*}{ Maternal affect negativity } & Emotional awareness & .18 & 1.10 & .19 & $3.07^{*}$ \\
\hline & Emotional acceptance & .05 & -.29 & & \\
\hline & Emotional regulation & $-.73^{* *}$ & -2.83 & & \\
\hline & Emotional awareness of child's emotion & .09 & .52 & .10 & 1.07 \\
\hline & Emotional acceptance of child's emotion & -.39 & -1.69 & & \\
\hline & Emotional coaching of child's emotion & .17 & .73 & & \\
\hline & Emotional regulation of child's emotion & -.01 & -.04 & & \\
\hline \multirow[t]{7}{*}{ Child affect negativity } & Emotional awareness & .13 & 2.34 & .02 & .30 \\
\hline & Emotional acceptance & .17 & .94 & & \\
\hline & Emotional regulation & .05 & .28 & & \\
\hline & Emotional awareness of child's emotion & -.08 & -.41 & .34 & $2.63^{*}$ \\
\hline & Emotional acceptance of child's emotion & -.05 & -.22 & & \\
\hline & Emotional coaching of child's emotion & $-.40^{*}$ & -.56 & & \\
\hline & Emotional regulation of child's emotion & -.10 & -.54 & & \\
\hline
\end{tabular}

Note. $N=44$.

${ }^{*} p<.05 .{ }^{* *} p<.01$.

Table 4

Correlations of Maternal Meta-Emotion Philosophy and Mother-Child Interaction Patterns

$\begin{array}{llllllllll}1 & 2 & 3 & 4 & 5 & 6 & 7 & 8 & 9 & 10\end{array}$

Meta-emotion philosophy

$1 \quad-$

$2.46^{* *}$

3.16

$4.41^{* *}$

$5 \quad .20$

$6.42^{* *}$

$.42^{* *}$

$-34^{*}$
$.32^{*}$
$.46^{* *}$
$.56^{* *}$
.15

$-$

$.34^{*}$

$-.06$

$.44^{* *}$

$-$

$7 \quad-.05$

.15

.27

$.53^{* *}$

$.45^{* *}$

.26

$.65^{* *}$

$-$

$.56^{* *} \quad .34^{*}$

Mother-child interaction pattern

$\begin{array}{ccccccccccc}8 & -.09 & -.07 & .41^{* *} & .05 & .04 & .22 & .22 & - & - \\ 9 & .12 & .04 & .16 & .09 & .40^{* *} & .13 & .12 & .01 & - \\ 10 & -.11 & -.42^{* *} & -.32^{*} & -.40^{* *} & -.03 & -.05 & -.20 & .00 & .03 \\ 11 & .09 & .21 & .01 & .09 & .02 & .07 & .00 & .01 & .00 & .00\end{array}$

Note. $N=44 ; 1$ = emotional awareness; 2 = emotional acceptance; 3 = emotional regulation; 4 = emotional awareness of child's emotion; $5=$ emotional acceptance of child's emotion; $6=$ emotional coaching of child's emotion; $7=$ emotional regulation of child's emotion; $8=$ maternal neutral emotion - child positive emotion; 9 = maternal positive emotion - child positive emotion; $10=$ maternal negative emotion - child negative emotion; 11 = maternal negative emotion - child neutral emotion.

${ }^{*} p<.05 .{ }^{* *} p<.01$. 
Table 5

Multiple Regression Analysis of Maternal Meta-Emotion Philosophy as as Predictor of Mother-Child Interaction Patterns

\begin{tabular}{|c|c|c|c|c|c|}
\hline Dependent variable & Independent variable & $\beta$ & $t$ & $R^{2}$ & $F$ \\
\hline Maternal neutral emotion - Child positive emotion & Emotional regulation & $.31^{* *}$ & 2.52 & .31 & $4.55^{*}$ \\
\hline Maternal positive emotion - Child positive emotion & Emotional acceptance of child's emotion & $.07^{*}$ & 2.40 & .38 & $5.77^{*}$ \\
\hline \multirow[t]{3}{*}{ Maternal negative emotion - Child negative emotion } & Emotional acceptance & $-.23^{*}$ & -2.35 & .34 & $5.52^{*}$ \\
\hline & Emotional regulation & $-.13^{*}$ & -2.13 & & \\
\hline & Emotional awareness of child's emotion & $-.17^{*}$ & -2.06 & & \\
\hline
\end{tabular}

Note. $N=44$.

${ }^{*} p<.05 .{ }^{* *} p<.01$.

반응패턴은 자녀의 정서에 대한 어머니의 수용에 영향을 받으 며, 그 설명력은 $38 \%$ 로 $(t=.07, p<.05)$, 회귀식이 통계적으로 유의미하였다 $(F=5.77, p<.05)$. 그리고 '어머니 부정정서 - 아 동 부정정서' 패턴은 어머니 자신의 정서 수용과 조절, 자녀의 정서에 대한 어머니의 인식이 영향을 미치는 것으로 나타났다 $(t=-.23, p<.05 ; t=-.13 p<.05 ; t=-.17, p<.05)$. 이 모형의 설 명력은 $34 \%$ 로 통계적으로 유의한 회귀식을 보였다 $(F=5.52$, $p<.05)$.

\section{논의 및 결론}

본 연구는 만 5세 자녀와 그들의 어머니 총 44 쌍을 대상으로 어머니의 상위정서철학이 실제 어머니-자녀 상호작용에서 나 타난 정서반응과 어떠한 관련이 있는지를 살펴보았다. 특별히 상호호혜적으로 반복되는 어머니-자녀 정서반응 간 패턴을 추출하여 어머니 상위정서철학 간의 관계를 탐색하였다. 이를 통해 발견된 연구결과들을 논의하고 연구의 시사점과 제한점 을 제시하고자 한다.

첫째, 어머니의 상위정서철학과 어머니-자녀 정서반응 간 의 관계를 살펴보면, 자신의 부정적 정서경험에 압도되지 않 고 이를 잘 조절하는 상위정서철학을 가진 어머니의 경우, 상 호작용 동안 자녀에게 분노와 같은 부정적 정서반응을 적게 보이는 것으로 나타났다. 자신의 부정정서를 잘 조절하는 상 위정서철학은 자신의 부정적 감정의 원인을 능숙하게 통제 하고 자신만의 극복기술을 가지고 있음을 의미하는 것으로, 이러한 어머니의 능력이 부정적 정서반응을 감소시키는 중 요한 변인으로 작용한 것으로 볼 수 있다. 이는 어머니의 정 서조절은 자녀를 향한 언어적, 비언어적 방식으로 표현되며, 자녀와의 상호작용에서 핵심적 역할을 밝힌 Landry, Smith, MillerLoncar와 Swank (1998)의 정서적 조율 모형을 지지한다.
즉, 자녀와의 상호작용에서 정서조절 수준이 낮은 어머니들 은 상승된 부정정서에 쉽게 압도되어 자신의 정서조절을 어려 워하고 해결되지 않은 정서를 자녀에게 그대로 드러내는 반 면(Nahm \& Park, 2017), 자신의 정서를 효과적으로 다루고 긍 정적인 정서에 초점을 맞추는 어머니의 정서조절 방식은 자신 뿐 아니라 자녀의 긍정적 정서반응과도 깊은 관련이 있음을 제안한다(Zhou et al., 2002).

다음으로 자녀의 부정정서에 대해 정서코칭을 잘 하는 상 위정서 철학을 보인 어머니일수록 상호작용에서 아동의 부정 정서반응이 낮게 나타났다. 정서코칭을 잘하는 부모는 자녀의 부정적 감정을 존중하며, 자녀가 정서적 어려움을 스스로 해 결하도록 돕는 일련의 상호작용을 통해 자녀와의 친밀도를 높 일 수 있다고 여긴다(Gottman et al., 1996; Gottman \& Nahm, 2007). 따라서, 정서코칭의 이러한 과정들은 자녀로 하여금 정 서를 어떻게 효율적으로 다루는지를 학습할 수 있는 기회를 제공하여 부정적 정서가 고조되기 전에 효과적인 정서조절을 가능하였다고 볼 수 있다. 실제로 어머니의 정서코칭은 자녀 가 또래와의 상호작용에서 부정적 정서를 적게 보이고, 보다 높은 놀이 수준에 기여하며(Katz \& Windecker-Nelson, 2004), 이후 자녀의 보다 적응적이고 주도적인 상위정서철학과도 관 련이 있음을 밝힌 바 있다(Hunter et al., 2011).

둘째, 어머니의 상위정서철학과 어머니-자녀의 상호호혜 적 정서반응패턴 간 관계에 있어, 어머니 자신의 정서조절 수 준이 '어머니 중립정서 - 자녀 긍정정서' 반응 패턴에 영향을 미치는 것으로 관찰되었다. 자신의 정서를 효과적으로 조절하 는 어머니가 실제 자녀와의 상호작용에서도 적절한 상호작용 이 가능함을 고려할 때(Katz \& Windecker-Nelson, 2004; Nahm $\&$ Park, 2017), 이들은 보다 능숙하게 자신의 부정적 정서경험 을 중립 혹은 긍정적 영역으로 전환할 수 있음을 가정해 볼 수 있다. 그러므로 이러한 결과는 어머니 자신의 정서조절 수준 이 실질적인 어머니-자녀 상호작용 내에서 자녀의 부정정서 
반응을 보호할 수 있는 요인임을 보여준다.

또한 상위정서철학을 통해 나타난 자녀의 부정정서에 대한 어머니의 높은 수용능력은 실제 상호작용에서 '어머니 긍정정 서 - 자녀 긍정정서' 반응패턴에 영향을 미치는 것으로 나타났 다. 즉, 자녀의 부정정서를 잘 수용하는 태도를 가진 어머니는 스트레스 상황 속에서 상호작용을 하는 동안 지속적으로 긍정 정서 반응을 표현하였고, 이에 자녀 역시 상호호혜적으로 긍 정정서반응을 보였음을 의미한다. 이러한 결과는 자녀의 부정 정서에 대한 어머니의 정서수용이 자녀와의 상호작용에서 풍 부한 긍정정서경험 및 정서적 연결감을 제공한다는 연구와 일 치한다(Bell \& Wolfe, 2004). 그 밖에 여러 연구들이 어머니의 긍정정서표현이 자녀의 긍정정서반응에 영향을 미친다고 보 고하고 있으나(McElwain, Halberstadt, \& Volling, 2007; Meyer et al., 2014), 본 연구는 더 나아가 자녀의 정서를 잘 수용하는 어머니의 상위정서철학이 어머니-자녀 정서적 교류의 순기능 을 보다 촉진 혹은 증가시킬 수 있음을 시사하였다.

마지막으로 어머니 자신의 부정정서를 능숙하게 수용하 고 조절하며, 자녀의 정서 또한 잘 인식하는 어머니의 상위정 서철학은 낮은 '어머니 부정정서 - 자녀 부정정서' 패턴 즉, 어 머니 부정정서반응에 자녀가 부정정서를 표현하는 빈도가 낮 게 나타났다. 흥미로운 점은 자녀의 부정정서를 잘 수용해주 는 어머니의 경우, ‘어머니 긍정정서 - 자녀 긍정정서' 반응이 증가하였으며, 반면 자신의 부정정서를 잘 수용하고 조절하는 어머니는 '어머니 부정정서 - 자녀 부정정서' 반응이 감소하였 다는 사실이다. 어머니-자녀의 상승된 스트레스 상호작용 상 황에서 자녀의 정서와 표현에 대한 수용적인 정서반응들은 어 머니의 전반적인 긍정적 분위기와 목소리 톤, 몸짓, 얼굴표정 등으로 표현되고 결과적으로 자녀의 긍정정서반응을 상승시 켰다고 볼 수 있다. 반면, 어머니 개인이 경험하는 부정적 정 서와 정서표출에 편안하게 반응하는 상위정서철학은 자신의 정서를 보다 잘 이해하도록 돕고(Kring, Smith, \& Neale, 1994), 상승된 부정정서를 잘 조절하여(Katz \& Windecker-Nelson, 2004), 어머니 자신 및 자녀의 부정적 패턴 감소에 영향을 미 쳤음을 확인하였다. 또한 어머니가 자녀의 정서를 잘 인식하 는 과정은 자녀와의 상호작용 동안 지속적으로 자녀의 얼굴표 정 및 행동변화에 관심을 가지고 아동의 언어적, 비언어적 요 구신호에 관심을 가지고 있음을 의미하며, 이러한 과정이 자 녀의 긍정적 상호작용을 도왔다고 볼 수 있다(Park \& Nahm, 2010). 이러한 결과들은 어머니 자신 및 자녀의 부정정서에 대 한 정서적 가치관이 어머니-자녀 상호작용 내 정서반응에 서 로 다른 기능으로 작용할 뿐 아니라 자녀와의 관계 속에서 단
순히 개인 차원에 머무는 것이 아니라 자녀와의 관계 속에서 의미있는 정서반응으로 나타나는 정서사회화 과정을 보여주 었다.

종합하면 본 연구는 다음과 같은 의의를 가진다. 첫째, 정서 사회화 과정 안에서 어머니의 상위정서철학이 실제 어머니자녀 상호작용에서 나타난 어머니와 자녀의 정서반응에 미치 는 영향을 밝혔고, 더 나아가 상호호혜적 정서반응패턴과 상 위정서철학 간의 관계를 확인하였다는 점에서 기존 선행연구 들과 차이점을 갖는다. 이러한 결과를 통해 자녀의 긍정적 혹 은 부정적 정서반응에 결정적 역할을 하는 어머니의 정서적 반응에 대한 상위정서철학의 직접적인 영향력을 입증하였으 며(Lunkenheimer, Shields, \& Cortina, 2007), 특히 종적인 정서 사회화 과정의 흐름을 실증적 연구를 통해 어머니-자녀 상호 작용 내 정서적 흐름을 횡적으로 탐색하여 정서사회화 과정을 설명하였다는데 그 의의가 있다. 둘째, 방법론적인 측면에 있 어, 상위정서인터뷰를 실시하여 정서경험에 대한 정보를 질적 으로 수집하고 이를 양적으로 코딩하였다. 또한 실제 어머니자녀의 상호작용을 관찰하기 위해 과제 실험을 실시하고 이를 컴퓨터 프로그램을 통해 초단위로 분석하였다. 과학적 측정을 통해 정서를 보다 심층적으로 접근하였으며, 기존 정서연구들 의 한계점을 보완하였다는데 또 다른 의의를 갖는다.

본 연구의 제한점 및 후속연구를 위한 제언은 다음과 같다. 먼저 본 연구는 관찰 및 인터뷰를 활용한 실험연구로서, 연구 대상 표집의 크기가 작아 일반화에 한계가 있다. 어머니 상위 정서철학과 관련된 국내 연구가 부족한 만큼 추후 연구에서는 대상의 확대와 더불어 연령과 성별 등 다양한 인구학적 변인 에 따른 차이를 고려해야할 것이다. 또한 본 연구는 보다 과학 적이고 정밀한 결과를 얻기 위해 양적인 연구방법을 사용하였 으나, 질적 연구방법을 함께 적용한다면 보다 깊이있는 결과 를 기대할 수 있을 것이다. 다음으로 어머니의 상위정서철학 측정 시, 슬픔과 분노 차원을 나누어 정보를 수집하였으나, 통 계적 검정력을 높이기 위해 부정정서라는 단일차원으로 분석 하였다. 슬픔과 분노를 대하는 어머니의 태도가 달랐다고 보 고한 일부 연구결과(Kim \& Nahm, 2013)로 미루어, 후속 연구 에서는 슬픔 및 분노 각각의 상위정서철학을 다루는 연구가 추가적으로 수행될 필요가 있다. 또한 개발된 상위정서인터 뷰 매뉴얼은 부정정서 외 긍정정서(애정과 자부심)에 대한 상 위정서철학을 담고 있으나, 긍정정서에 대한 상위정서철학 코 딩체계의 미비로 아직 접근을 시도하지 못하고 있다. 후속연 구에서 긍정정서 상위정서철학 코딩체계 구조의 검증 및 신뢰 도와 타당도를 확보한다면 상위정서철학의 보다 다양한 측면 
을 고려할 수 있을 것으로 보인다. 끝으로 아버지와 어머니는 양육행동에 있어 유사한 신경회로, 호르몬 및 신경 조절인자 를 보이는 것으로 보고되고 있지만(Leuner, Glasper, \& Gould, 2010) 다수의 연구들은 아버지와 어머니의 서로 다른 양육 매 커니즘을 밝히고 있다(Cassano, Perry-Parrish, \& Zeman, 2007; Lonstein \& De Vries, 2000). 추후 아버지의 상위정서철학과 실 제 아버지-자녀 상호작용 내 정서적 교류에 대한 연구를 확충 한다면 우리나라 부모와 자녀 상호작용의 정서적 특성을 규명 하고 이들을 위한 중재프로그램 개발의 유용한 자료가 될 수 있을 것이다.

\section{Acknowledgements}

This work was supported by a research grant from Seoul Women's University (2018).

\section{Notes}

This article was presented as a poster at 2017 Fall Conference of Child Studies Association.

\section{Conflict of Interest}

No potential conflict of interest relevant to this article was reported.

\section{References}

\section{In English}

Bell, M. A., \& Wolfe, C. D. (2004). Emotion and cognition: An intricately bound developmental process. Child Development, 75(2), 366-370. doi:10.1111/j.1467-8624.2004.00679.x

Bernier, A., Carlson, S. M., \& Whipple, N. (2010). From external regulation to self-regulation: Early parenting precursors of young children's executive functioning. Child Development, 81(1), 326-339. doi:10.1111/j.1467-8624.2009.01397.x

Carson, J. L., \& Parke, R. D. (1996). Reciprocal negative affect in parent-child interactions and children's peer competency. Child Development, 67(5), 2217-2226. doi:10.1111/j.1467- 8624.1996.tb01853.x

Cassano, M., Perry-Parrish, C., \& Zeman, J. (2007). Influence of gender on parental socialization of children's sadness regulation. Social Development, 16(2), 210-231. doi:10.1111/ j.1467-9507.2007.00381.x

Cervantes, C. A., \& Seo, M. (2005). Korean mothers' beliefs about children's emotions: An examination of parenting in a multicultural context. In JC Dunsmore (Chair), Multicultural examination of parent's beliefs about children: Meanings, mechanisms, and methods. Symposium Conducted at the Biennial Meeting of the Society for Research in Child Development, Atlanta, GA.

Chen, F. M., Lin, H. S., \& Li, C. H. (2012). The role of emotion in parent-child relationships: Children's emotionality, maternal meta-emotion, and children's attachment security. Journal of Child and Family Studies, 21(3), 403-410. doi:10.1007/s10826-011-9491-y

Dunsmore, J. C., \& Karn, M. A. (2001). Mothers' beliefs about feelings and children's emotional understanding. Early Education and Development, 12(1), 117-138. doi:10.1207/ s15566935eed1201_7

Fischer, A. H., \& Manstead, A. S. R. (2008). Social functions of emotion. In M. Lewis, J. M. Haviland-Jones, \& L. F. Barrett (3rd Ed.), Handbook of Emotions (pp. 456-468). New York: Guilford Press.

Gottman, J. M., Katz, L. F., \& Hooven, C. (1996). Parental metaemotion philosophy and the emotional life of families: Theoretical models and preliminary data. Journal of Family Psychology, 10(3), 243-268. doi:10.1037/08933200.10.3.243

Gottman, J. M., Katz, L. F., \& Hooven, C. (1997). Meta-emotion: How families communicate emotionally. Mahwah, NJ: Erlbaum.

Halberstadt, A. G., Thompson, J. A., Parker, A. E., \& Dunsmore, J. C. (2008). Parents' emotion-related beliefs and behaviours in relation to children's coping with the 11 September 2001 terrorist attacks. Infant and Child Development, 17(6), $557-$ 580. doi:10.1002/icd.569

Hunter, E. C., Katz, L. F., Shortt, J. W., Davis, B., Leve, C., Allen, N. B., \& Sheeber, L. B. (2011). How do I feel about feelings? Emotion socialization in families of depressed and healthy adolescents. Journal of Youth and Adolescence, 40(4), 428-441. doi:10.1007/s10964-010-9545-2

Jolliffe I. T. (2002). Principal component analysis. New York: Springer Science \& Business Media.

Katz, L. F., \& Gottman, J. M. (1986). The meta-emotion interview (Unpublished manual). Seattle, WA: University of Washington.

Katz, L. F., \& Hunter, E. C. (2007). Maternal meta-emotion philosophy and adolescent depressive symptomatology. Social 
Development, 16(2), 343-360. doi:10.1111/j.1467-9507. 2007.00388.x

Katz, L. F., Maliken, A. C., \& Stettler, N. M. (2012). Parental meta-emotion philosophy: A review of research and theoretical framework. Child Development Perspectives, 6(4), 417-422. doi:10.1111/j.1750-8606.2012.00244.x

Katz, L. F., Mittman, A. \& Hooven, C. (1994). The meta-emotion coding system. (Unpublished manuscript). Seattle, WA: University of Washington.

Katz, L. F., \& Windecker-Nelson, B. (2004). Parental metaemotion philosophy in families with conduct-problem children: Links with peer relations. Journal of Abnormal Child Psychology, 32(4), 385-398. doi:10.1023/B:JACP. 0000030292.36168 .30

Kelly, J. F., \& Barnard, K. E. (2000). Assessment of parentchild interaction: Implications for early intervention. In J. P Shonkoff \& S. J. Meisels (2nd Ed.), Handbook of Early Childhood Intervention (pp. 258-289). New York: Cambridge University Press.

Kring, A. M., Smith, D. A., \& Neale, J. M. (1994). Individual differences in dispositional expressiveness: development and validation of the Emotional Expressivity Scale. Journal of personality and social psychology, 66(5), 934-949. Retrieved from https:/www.researchgate.net/publication/15184081

Krippl, M., Ast-Scheitenberger, S., Bovenschen, I., \& Spangler, G. (2010). Maternal perception of infants' expressions of emotion. Journal of Psychophysiology. 24, 173-185. doi:10.1027/0269-8803/a000008

Landry, S. H., Smith, K. E., Miller-Loncar, C. L., \& Swank, P. R. (1998). The relation of change in maternal interactive styles to the developing social competence of full-term and preterm children. Child Development, 69(1), 105-123. doi:10.1111/j.1467-8624.1998.tb06137.x

Leuner, B., Glasper, E. R., \& Gould, E. (2010). Parenting and plasticity. Trends in Neurosciences, 33(10), 465-473. doi:10.1016/j.tins.2010.07.003

Lonstein, J. S., \& De Vries, G. J. (2000). Sex differences in the parental behavior of rodents. Neuroscience \& Biobehavioral Reviews, 24(6), 669-686. doi:10.1016/S0149-7634(00) 00036-1

Lunkenheimer, E. S., Shields, A. M., \& Cortina, K. S. (2007). Parental emotion coaching and dismissing in family interaction. Social Development, 16(2), 232-248. doi:10.1111/ j.1467-9507.2007.00382.x

Mangold, P. (2008). INTERACT (version 8.7.1) [Computer software]. Arnstorf, Germany: Mangold International $\mathrm{GmbH}$.

McElwain, N. L., Halberstadt, A. G., \& Volling, B. L. (2007). Mother-and father-reported reactions to children's negative emotions: Relations to young children's emotional understanding and friendship quality. Child Development, 78(5), 1407-1425. doi:10.1111/j.1467-8624.2007.01074. $\mathrm{x}$

Meyer S., Raikes H. A., Virmani E. A., Waters S., \& Thompson R. A.. (2014). Parent emotion representations and the socialization of emotion regulation in the family. International Journal of Behavioral Development, 38(2), 164-173. doi:10.1177/0165025413519014

Morey, J. N., Gentzler, A. L., Creasy, B., Oberhauser, A. M., \& Westerman, D. (2013). Young adults' use of communication technology within their romantic relationships and associations with attachment style. Computers in Human Behavior, 29(4), 1771-1778. doi:10.1016/j.chb.2013.02.019

Nahm, E. Y. (2006). A cross-cultural comparison of Korean American and European American parental meta-emotion philosophy and its relationship to parent-child interaction. Retrieved from https://www.researchgate.net/publication/33519650.

Norman, E., \& Furnes, B. (2016). The concept of "meta emotion": What is there to learn from research on meta cognition? Emotion Review, 8(2), 187-193. doi:10.1177/1754073914552913

Osofsky, J. D., \& Thompson, M. D. (2000). Adaptive and maladaptive parenting: Perspectives on risk and protective factors. In J. P Shonkoff \& S. J. Meisels (2nd Ed.), Handbook of Early Childhood Intervention (pp. 54-75). New York: Cambridge University Press.

Paavola, L., Kunnari, S., \& Moilanen, I. (2005). Maternal responsiveness and infant intentional communication: Implications for the early communicative and linguistic development. Child: Care, Health and Development, 31(6), 727-735. doi:10.1111/j.1365-2214.2005.00566.x

Salovey, P., \& Mayer, J. D. (1990). Emotional intelligence. Imagination, Cognition and Personality, 9(3), 185-211. doi:10.2190/DUGG-P24E-52WK-6CDG

Shortt, J. W., Stoolmiller, M., Smith-Shine, J. N., Eddy, M. J., \& Sheeber, L. (2010). Maternal emotion coaching, adolescent anger regulation, and siblings' externalizing symptoms. Journal of Child Psychology and Psychiatry, 51(7), 799-808. doi:10.1111/j.1469-7610.2009.02207.x

Siegel, D. J. (1999). The developing mind (Vol. 296). New York: Guilford Press.

Stettler, N., \& Katz, L. F. (2014). Changes in parents' meta-emotion philosophy from preschool to early adolescence. Parenting, 14(3-4), 162-174. doi:10.1080/15295192.2014.945584

Webster-Stratton, C., Reid, M. J., \& Hammond, M. (2004). Treating children with early-onset conduct problems: Intervention outcomes for parent, child, and teacher training. Journal of Clinical Child and Adolescent Psychology, 33(1), 105-124. doi:10.1207/S15374424JCCP3301_11

Wong, M. S., Diener, M. L., \& Isabella, R. A. (2008). Parents' emotion related beliefs and behaviors and child 
grade: Associations with children's perceptions of peer competence. Journal of Applied Developmental Psychology, 29(3), 175-186. doi:10.1016/j.appdev.2008.02.003

Zhou Q., Eisenberg N., Losoya S. H., Fabes R. A., Reiser M., Guthrie I. K., . . S Shepard S. A.. (2002). The relations of parental warmth and positive expressiveness to children's empathy-related responding and social functioning: A longitudinal study. Child Development 73(3), 893-915. doi:10.1111/1467-8624.00446

\section{In Korean}

Choi, R. \& Nahm, E. (2016). The relations between maternal meta-emotion philosophy, child interpersonal problem solving, and peer competence. Korean Journal of Child Studies, 37(4), 57-67. doi:10.5723/kjcs.2016.37.4.57

Gottman J. M., Nahm E. Y.. (2007). Raising an emotionally intelligent child: The heart of parenting. Seoul: Hankyung BP.

Jeong, Y. \& Park, H. (2012). Korean parent's belief about children's emotion and emotion related parenting. The Korean Journal of Developmental Psychology, 25(2), 107-128.

Kim, J. \& Nahm, E. (2013). Relations between mother-child communication and the quality of peer relationship. The Journal of the Korean Association of Psychotherapy, 5(2), 3549.

Nahm, E. Y. \& Park, S. E. (2017). Mother-child interactions in a stressful situation by mother's emotional regulation level. Korean Journal of Child Studies, 38(1), 251-262. doi:10.5723/kjcs.2017.38.1.251

Park, S. E. \& Nahm, E. (2010). The relationship of mother's emotional expressiveness, awareness, acceptance and parenting attitude: A comparison of low income and middle income families. The Korean Journal of Developmental Psychology, 23(3), 89-103.

Shin, N., Park, B., Kim. S., \& Doh, H.-S. (2015). Reciprocal relations between parenting behavior and preschoolers' compliance/noncompliance during mother-child interactions : A short-term longitudinal study. Korean Journal of Child Studies, 36(5). 75-94. doi:10.5723/kjcs.2015.36.5.75

Song, S. \& Nahm, E. (2013). Relations between maternal metaemotion philosophy and children's social competence: Focused on the mediation effects of children's metaemotion philosophy. The Korean Journal of Developmental Psychology, 26(3), 1-20.

\section{ORCID}

Eun Young Nahm

So Eun Park http://orcid.org/0000-0002-5717-7961

http://orcid.org/0000-0003-0647-2597
Received April 30, 2018

Revision received June 24, 2018

Accepted August 2, 2018 